OPEN ACCESS

Edited by: Gaetano Cairo,

Università degli Studi di Milano, Italy

Reviewed by:

Qingxin Mu,

University of Washington

United States

Joseph Erlichman,

St. Lawrence University, United States

*Correspondence:

Fanny Caputo

fanny.caputo@gmail.com

Enrico Traversa

traversa@uestc.edu.cn

Lina Ghibelli

ghibelli@uniroma2.it

Specialty section: This article was submitted to Experimental Pharmacology

and Drug Discovery,

a section of the journal

Frontiers in Pharmacology

Received: 25 July 2018 Accepted: 28 September 2018

Published: 16 October 2018

Citation:

Caputo F, Giovanetti A, Corsi F Maresca V, Briganti S, Licoccia S,

Traversa E and Ghibelli L (2018)

Cerium Oxide Nanoparticles

Re-establish Cell Integrity

Checkpoints and Apoptosis Competence in Irradiated HaCat Cells via Novel Redox-Independent Activity.

Front. Pharmacol. 9:1183.

doi: 10.3389/fphar.2018.01183

\section{Cerium Oxide Nanoparticles} Re-establish Cell Integrity Checkpoints and Apoptosis Competence in Irradiated HaCat Cells via Novel Redox-Independent Activity

\author{
Fanny Caputo ${ }^{1,2 *}$, Anna Giovanetti ${ }^{3}$, Francesca Corsi ${ }^{1}$, Vittoria Maresca ${ }^{4}$, \\ Stefania Briganti ${ }^{4}$, Silvia Licoccia ${ }^{1}$, Enrico Traversa ${ }^{5 *}$ and Lina Ghibelli1* \\ ${ }^{1}$ Department of Chemical Science and Technologies, University of Rome Tor Vergata, Rome, Italy, ${ }^{2}$ Department of Biology, \\ University of Rome Tor Vergata, Rome, Italy, ${ }^{3}$ ENEA SSPT-TECS-BIORISC, Rome, Italy, ${ }^{4}$ San Gallicano Dermatological \\ Institute IRCCS, Rome, Italy, ${ }^{5}$ School of Materials and Energy, University of Electronic Science and Technology of China, \\ Chengdu, China
}

Cerium oxide nanoparticles (CNPs) are potent radical scavengers protecting cells from oxidative insults, including ionizing radiation. Here we show that CNPs prevent X-ray-induced oxidative imbalance reducing DNA breaks on HaCat keratinocytes, nearly abating mutagenesis. At the same time, and in spite of the reduced damage, CNPs strengthen radiation-induced cell cycle arrest and apoptosis outcome, dropping colony formation; notably, CNPs do not possess any intrinsic toxicity toward nonirradiated HaCat, indicating that they act on damaged cells. Thus CNPs, while exerting their antioxidant action, also reinforce the stringency of damage-induced cell integrity checkpoints, promoting elimination of the "tolerant" cells, being in fact radiosensitizers. These two contrasting pathways are mediated by different activities of CNPs: indeed Sm-doped CNPs, which lack the $\mathrm{Ce}^{3+} / \mathrm{Ce}^{4+}$ redox switch and the correlated antioxidant action, fail to decrease radiation-induced superoxide formation, as expected, but surprisingly maintain the radio-sensitizing ability and the dramatic decrease of mutagenesis. The latter is thus attributable to elimination of damaged cells rather than decreased oxidative damage. This highlights a novel redox-independent activity of CNPs, allowing selectively eliminating heavily damaged cells through nontoxic mechanisms, rather reactivating endogenous anticancer pathways in transformed cells.

Keywords: cerium oxide nanoparticles, apoptosis, radio-sensitization, DNA damage response, anticancer therapy, DNA integrity checkpoints 


\section{INTRODUCTION}

Cerium oxide nanoparticles (CNPs) are attracting much interest in biomedical applications for their anti-oxidant properties provided by the $\mathrm{Ce}^{3+} / \mathrm{Ce}^{4+}$ redox couple on the nanoparticles surface, which combine catalase- and superoxide dismutase (SOD)-mimetic activities scavenging hydrogen peroxide and superoxides in a self-regenerating manner (Das et al., 2013). Coupled with high biocompatibility (Park et al., 2008; O’Brien and Cummins, 2010), protection from oxidative damage and cell death (Celardo et al., 2011b), and amelioration of oxidative pathologies (D'Angelo et al., 2009), the peculiar antioxidant properties of CNPs are considered very promising pharmacological tools (Walkey et al., 2015). In particular, CNPs have been shown to act as radio-protective agents (Tarnuzzer et al., 2005), an ability that is generally attributed to scavenging of radiation-induced oxidative stress (Colon et al., 2010).

Cerium oxide nanoparticles show intriguing potential anticancer effects (Corsi et al., 2018), reducing tumor growth in animal models (Giri et al., 2013), and ameliorating malignant features of cancer microenvironment such as neo-angiogenesis (Giri et al., 2013; Lord et al., 2013) and stroma-tumor altered communications (Alili et al., 2011). CNPs show additional intriguing anticancer properties: they ameliorate the effect of radiotherapy increasing killing of tumor cells (Wason et al., 2013), a major issue considering that cancer cell radio-resistance is a main obstacle to successful radiotherapy; moreover, CNPs seem to be preferentially toxic in cancer vs. non-transformed cells (Sack et al., 2014). The mechanisms of such effects are still unclear: indeed, they cannot be satisfactorily explained by radical scavenging, suggesting that they may be the result of other, still poorly understood non-redox CNPs properties. For example, it has been proposed that CNPs dissolution occurring in particular conditions such as, e.g., acidic environment at $\mathrm{pH} \leq 4$ (Schwabe et al., 2014) or irradiation in water media (Asghar et al., 2017), may exert noxious effect, through liberation of the cytotoxic $\mathrm{Ce}^{4+}$ ions (Huang et al., 2010); an additional effect of the acidic environment is the inhibition of the catalase-mimetic activity of CNPs while the SOD-mimetic ability is preserved: this would lead to accumulation of $\mathrm{H}_{2} \mathrm{O}_{2}$, more toxic than superoxides, and a paradoxical oxidative stress (Perez et al., 2008). Such interpretations, however, must face the fact that on one side, $\mathrm{pH}>4$ does not cause CNPs alterations, and on the other, tissues and cells, though stressed or transformed, would collapse at $\mathrm{pH} \leq 4$ : therefore, alternative explanations are required to understand the mechanism of the non-redox activities of CNPs.

A straightforward method to assess which CNPs actions depend on the redox activity, is probing the system with CNPs doped with $\mathrm{Sm}$, a lanthanide with stable $3+$ valence that substitutes $\mathrm{Ce}^{3+}$ ions in the lattice, pinning Ce valence at 4+ (Celardo et al., 2011a; Caputo et al., 2015). This way, the $\mathrm{Ce}^{3+} / \mathrm{Ce}^{4+}$ redox switch is eliminated, whereas the surface oxygen vacancies necessary to compensate the lack of +4 valence in CNPs are preserved. Upon Sm doping, we could demonstrate that the ability of CNPs to inhibit apoptosis in cells of blood origin is due to the redox switch (Celardo et al., 2011a; Caputo et al., 2015, 2017), whereas the impairment of neuronal cell differentiation is not (Gliga et al., 2017): this indicates that other features of CNPs, additional to the redox switch, may exert redox-independent biological activity.

In this study, we describe two novel unexpected findings, showing that CNPs, in addition to act as radio-protecting agents, are able to: (1) act as radio-sensitizers by restoring damageinduced intracellular checkpoints and apoptosis competence; and (2) exert this action with a mechanism independent from the $\mathrm{Ce}^{3+} / \mathrm{Ce}^{4+}$ redox switch.

\section{MATERIALS AND METHODS}

\section{CNP and SDC Synthesis and Characterization}

Cerium oxide nanoparticles (CNPs) and Sm-doped Ceria (SDC) were synthesized and characterized as follows. Briefly, Pluronic F-127 (Sigma-Aldrich) surfactant was dissolved in $300 \mathrm{~mL}$ of deionized water at a concentration of $0.8 \mathrm{~g} \mathrm{~mol}^{-1}$. After $1 \mathrm{~h}$, $12.4 \mathrm{~g}$ of cerium (III) nitrate hexahydrate $\left(\mathrm{Ce}\left(\mathrm{NO}_{3}\right) 36 \mathrm{H}_{2} \mathrm{O}\right)$ or a mixture of $\mathrm{Ce}(\mathrm{NO} 3) 3 \times 6 \mathrm{H}_{2} \mathrm{O}$ and $\mathrm{Sm}\left(\mathrm{NO}_{3}\right) 3 \times 6 \mathrm{H}_{2} \mathrm{O}$ (Aldrich, Milano, Italy) in the right stoichiometric proportion were poured into the solution, followed by the addition of $13 \mathrm{~mL}$ of N,N,N0,N0-tetramethylethylenediamine (TEMED) (Aldrich, Milano, Italy). The solution was kept overnight under mild stirring. The precipitated gel was collected by micro filtration, rinsed repeatedly with deionized water and placed in oven at $80^{\circ} \mathrm{C}$. The dehydrated material was grounded in an agate mortar and then annealed overnight at $450^{\circ} \mathrm{C}$ for $4 \mathrm{~h}$. The CNPs or SDC obtained were characterized by powder X-Ray diffraction (XRD) and transmission electron microscopy (TEM) analysis. Phase and morphology of the materials were analyzed using an XRD diffractometer (Philips X-Pert). Nanoparticle size was determined using a TEM (FEI Titan G2 60-300 ST Cs-Image corrected) microscope. Specific surface area measurements (BET analysis) were performed treating the samples in helium flux at $300^{\circ} \mathrm{C}$ for $1 \mathrm{~h}$ using a Micromeritics Gemini V equipment.

Details and figures are available in Supplementary Material.

A stock dispersion of CNPs or SDC were prepared in deionized water at the concentration of $20 \mathrm{mg} / \mathrm{mL}$. NPs were dispersed with ultrasounds (Branson Ultrasonic Corp., Danbury, CT, United States) at 20\% amplitude for $5 \mathrm{~min}$, and immediately diluted at the final concentration of $200 \mu \mathrm{g} / \mathrm{mL}$ in fresh medium. Nanoparticles were added to the cultures $1 \mathrm{~h}$ prior to all irradiations.

The dose was selected according to results described in Celardo et al. (2011a), where it was shown that a plateau was reached at the concentration of $200 \mu \mathrm{g} / \mathrm{mL}$.

\section{Cell Culture}

HaCat cells, a non-tumorigenic, spontaneously transformed human keratinocyte cell line, were grown at $37^{\circ} \mathrm{C}$ in a $5 \%$ $\mathrm{CO} 2$ humidified atmosphere in DMEM (4.5 g/liter glucose, $10 \%$ fetal calf serum, 100,000 units/liter penicillin, $50 \mathrm{mg} / \mathrm{L}$ streptomycin, and $200 \mathrm{mM}$ glutamine). Initial seeding densities or longer growth periods are chosen depending on experimental requirements. Depending on the end point to be studied, $\mathrm{HaCaT}$ 
cells are seeded in different types of plastic flasks. Such cells were selected because they lack proper DNA damage response (DDR, mimicking in this sense a cancer system), and are a reference model for X-rays response (Boukamp et al., 1999).

\section{Cell Irradiation}

Cells were irradiated at $80 \%$ confluence with $0.1,1,5$, or 7 Gy of X-rays generated by CHF $320 \mathrm{G}$ generator (Gilardoni, Mandello del Lario, Italy) equipped with a $\mathrm{Cu}$ filter of $0.5 \mathrm{~mm}$, operating at $250 \mathrm{keV}, 5 \mathrm{~mA}$, delivering a dose rate of $0.11 \mathrm{~Gy} / \mathrm{min}$.

\section{Reagents}

Dihydroethidium (DHE), dichlorofluorescein (DCF), regular melting point agarose, low melting point agarose, and all the other chemicals were purchased from Sigma-Aldrich (St. Louis, MO, United States). Stock solutions: DHE (5 mM) and DHR (10 mM) were dissolved in dimethyl sulfoxide (DMSO).

\section{Quantification of GSH}

Glutathione (GSH) levels were determined in cell lysates by high-performance liquid chromatography-mass spectrometry (HPLC-MS). Briefly, HaCat cells were lysed in aqueous solution containing $10 \mathrm{mM}$ N-ethylmaleimide (Sigma-Aldrich, St. Louis, MO, United States), and kept on ice for $30 \mathrm{~min}$. After centrifugation, the protein content was measured in the supernatants according to Bradford. Thereafter, $20 \mathrm{mM}$ thiosalicylic acid (TSA) (Sigma-Aldrich, St. Louis, MO, United States) was added, as internal standard, and the mixture was kept on ice for another $20 \mathrm{~min}$ to allow the derivatization of TSA. Acetonitrile was added to precipitate proteins. After centrifugation at $10,000 \mathrm{~g}$ for $5 \mathrm{~min}$, supernatants were injected and analyzed by a combined HPLC-MS system (Agilent Technologies, Palo Alto, CA, United States). The mean value of three measurements is given as GSH in nanomoles per milligram of total proteins $\pm \mathrm{SD}$.

\section{Assessment of Cell Membrane Fatty Acid Concentrations}

Cell pellets were extracted twice in chloroform/methanol (2/1, $\mathrm{v} / \mathrm{v})$ in the presence of $50 \mu \mathrm{g}$ butylated hydroxytoluene as antioxidant and $25 \mu \mathrm{g}$ of tricosanoic acid methyl ester as internal standard. Chloroform extracts were dried under nitrogen. Fatty acids of cell total lipid extract were trans-methylated with sodium methoxide $(15 \% \mathrm{w} / \mathrm{v})$ in methanol and analyzed by gas chromatography-mass spectrometry (GC-MS) on a capillary column (FFAP, $60 \mathrm{~m} \times 0.32 \mu \mathrm{m} \times 0.25 \mathrm{~mm}$, Hewlett Packard, Palo Alto, CA, United States). The results were calculated after time integration of the chromatogram and final processing of areas. The identity of each fatty acid was obtained by comparing the mass spectrum of a standard mixture of fatty acids (SigmaAldrich, St. Louis, MO, United States). Results are given as mean of three different lipid extractions \pm SD.

\section{Detection of ROS}

Reactive oxygen species (ROS) were measured in a 96-well plate assay using the fluorescent probe dihydrodichlorofluorescein diacetate (H2DCFDA), which is de-acetylated upon cell internalization; oxidation to DCF by the cell environment (preferentially peroxides) renders the probe fluorescent. HaCat cells were incubated with $10 \mu \mathrm{M}$ H2DCFDA in complete medium for $20 \mathrm{~min}$ at $37^{\circ} \mathrm{C}$. DCF fluorescence was measured at $5 \mathrm{~min}$ after irradiation and was analyzed using a Victor plate reader set at an excitation wavelength of $485 \mathrm{~nm}$ and emission wavelength of $535 \mathrm{~nm}$.

\section{Detection of Superoxides}

Superoxides were assayed using $5 \mu \mathrm{M}$ DHE (excitation $370 \mathrm{~nm} /$ emission $420 \mathrm{~nm}$ ), which is sensitive to oxidation by superoxide. DHE was added directly to the cell samples after irradiation and incubated at $37^{\circ} \mathrm{C}$ in the dark for $20 \mathrm{~min}$; then 20,000 cells for each sample were detached and analyzed by FACSCalibur flow cytometer. Data are analyzed with WinMdi 2.9 software.

\section{Catalase Activity}

Catalase activity was measured by spectrophotometrically monitoring the rate of disappearance of $10 \mathrm{mM}$ hydrogen peroxide at $240 \mathrm{~nm}$ (Aebi, 1984). One unit of Cat was defined as the amount of enzyme that degrades $1 \mu \mathrm{M}$ of $\mathrm{H}_{2} \mathrm{O}_{2}$. Standard curves were performed using human Cat at different concentrations. The mean of three different measurements was calculated and the results are given as units of Cat per milligram proteins \pm SD.

\section{Comet Assay}

Comet assay is a single-cell gel electrophoresis method that allows detecting DNA breaks (Giovanetti et al., 2008). Alkaline comet assay permits to detect both single and double strand brakes whereas neutral comet assay allows to selectively detect double strand breaks (DSBs). One hour after irradiation (unless otherwise stated) cells were suspended in $0.5 \%$ low melting point agarose then pipetted onto a frosted glass microscope slide pre-coated with a layer of $0.2 \%$ normal melting point agarose. Slides were incubated in the alkaline lysis solution for $1 \mathrm{~h}$. After lysis, slides were rinsed with electrophoresis buffer for $20 \mathrm{~min}$ to allow DNA unwinding. Alkaline comet assay electrophoresis buffer was prepared dissolving in deionized water 2.5 M NaCl; $100 \mathrm{mM}$ EDTA; $10 \mathrm{mM}$ Trizma base, and $\mathrm{NaOH}$ to reach $\mathrm{pH} 10$, while neutral comet assay electrophoresis buffer was made dissolving Tris-Base (2 M), Acetic acid (1 M), and EDTA $(50 \mathrm{mM})$ to reach $\mathrm{pH}$ 8. Electrophoresis was conducted for $30 \mathrm{~min}$ at $20 \mathrm{~V}$ with $300 \mathrm{~mA}$ in a unit Sub cell GT System $/ 15 \mathrm{~cm} \times 25 \mathrm{~cm}$ system equipped with Power Pack 300 (Bio-Rad Laboratories Inc., Hercules, CA, United States). In alkaline comet assay, slides were then gently washed in neutralization buffer solution for $5 \mathrm{~min}$. This step was not necessary in the neutral Comet procedure. Then, slides were dehydrated with ethanol series, and dried at room temperature. One hundred cells on each slide were scored using a fluorescence microscope; the extent of genetic damage was evaluated by visual scoring provided in arbitrary units after validation by comparison with computer image analysis (García et al., 2004). 


\section{Cell Cycle Analysis}

Cell suspensions were washed with PBS and fixed overnight in ethanol $70 \%$ at $-20^{\circ} \mathrm{C}$, treated with RNAse at $200 \mu \mathrm{g} / \mathrm{mL}$, stained with PI at the final concentration of $50 \mu \mathrm{g} / \mathrm{mL}$ and finally 20,000 cells for each sample were analyzed by FACSCalibur flow cytometer. Data were analyzed with WinMdi 2.9 software. Cells population in G1 and in G2 phases were estimated by gating the area of the relative peaks, and G2/G1 ratio was calculated.

\section{Evaluation of Apoptosis}

Apoptosis was evaluated quantifying the fraction of apoptotic nuclei by fluorescence microscopy after DNA staining with the cell-permeable specific dye Hoechst 33342, directly added to the cell culture. To evaluate the eventual presence of necrotic cells, cells were also stained with PI at a final concentration of $5 \mu \mathrm{g} / \mathrm{mL}$. The fraction of apoptotic nuclei among the total cell population was calculated by counting at the fluorescence microscope at least 300 cells in at least three randomly selected microscopic fields (Ghibelli et al., 1995).

\section{Clonogenic Cell Survival Assays}

Immediately after exposure to X-rays cells were trypsinized. After cell quantification with a Burker counting chamber, duplicate 60-mm tissue culture dishes were seeded with aliquots of 200 cells $/ \mathrm{mL}$ each. Colonies were allowed to form for 14 days, after which they were fixed with methanol and stained with crystal violet.

\section{Micronuclei Assay}

The micronuclei test is a broad-spectrum mutagenesis test (Furness et al., 2010). Micronuclei are small nuclear bodies arising from improper chromosome separation at mitosis as a consequence of chromosomal lost or mis-repaired DNA damage. Evaluation of the number of micronuclei among cells undergoing the mitotic telophase is a measure of early mutagenesis after genotoxic treatments. After irradiation, cytochalasin B $(3 \mu \mathrm{g} / \mathrm{mL}$; Sigma-Aldrich) was added to the cells to prevent cell division without inhibiting mitosis. After $24 \mathrm{~h}$, the resulting bi-nucleated cells label those that underwent mitosis. Then the medium was removed, the cells were rinsed with PBS, treated with hypotonic solution $(\mathrm{KCl} 0.075 \mathrm{M})$ for $3 \mathrm{~min}$ and then fixed by Carnoy fixative (methanol/acetic acid, 20:1) for $8 \mathrm{~min}$ and then stained with Hoechst 33342. A total of 500 bi-nucleated cells were scored under a fluorescent microscope; the values given in the graphs represent the number of micronuclei per 500 bi-nucleated cells.

\section{Statistical Analysis}

Each experiment was repeated $\geq 3$ times. Data are presented as means \pm SD. Statistical evaluation was conducted by a one-way ANOVA, followed by Tukey's Multiple Comparison Test (Homogeneous Variances) using the software Origin 8.0. Statistical significance was set at $p<0.05$.

\section{RESULTS}

\section{CNPs Decrease X-Ray-Induced Oxidation and DNA Damage}

HaCat cells irradiation with $0.1,1$, and 5 Gy of X-rays increases intracellular superoxides (DHE signal, Figure 1A) and peroxides (DCF signal, Figure 1B), measured as fluorescence emitted by the relative probes when oxidized. The increase is inhibited by CNPs, which maintain the values of both types of ROS at basal, i.e., pre-irradiation, levels. Among the consequences of ROS increase, Figure 1C shows that X-ray irradiation dosedependently and significantly decreases the levels of intracellular GSH, the most abundant endogenous molecular antioxidant responsible for preserving a reduced cytosolic redox state and protein conformation (Filomeni et al., 2002), and almost depletes cell membranes of poly-unsaturated fatty acids (PUFAs), the main reservoir of oxidizable double-bonds protecting membrane integrity from oxidative stress (Figure 1D). CNPs restore GSH and PUFAs concentration to levels similar to untreated cells. Importantly, CNPs also restore the intracellular catalase activity that was inhibited by irradiation (Figure 1E), without affecting protein level (controlled by Western blotting, data not shown), showing that CNPs exert a potent antioxidant action on the irradiated cells.

Another major consequence of X-ray irradiation is damage to DNA, which is especially sensitive to breaks to the sugarphosphate chain induced directly by the ionizing radiation, forming DSB, and indirectly by radiation-induced ROS, forming single strand breaks (SSBs) (Barcellos-Hoff et al., 2005; BorregoSoto et al., 2015). Here, we report that X-rays dose-dependently produced early SSB (Figure 2A) and DSB (Figure 2B) in HaCat cell DNA, as assessed by alkaline or neutral comet assay, respectively, at $1 \mathrm{~h}$ post-irradiation. CNPs strongly protected from SSB formation, maintaining basal levels at all doses. CNPs exerted only a partial protection against DSB, possibly dealing with the fraction of DSB resulting from vicinal SSB formed in opposite DNA strands, which are conceivably of an oxidative origin. CNPs accelerate DNA repair (Figure 2), confirming what previously reported (Caputo et al., 2015), completely sealing SSB at all doses after $24 \mathrm{~h}$. Notably, CNPs act as antioxidant agents also in non-irradiated cells, slightly reducing oxidative parameters and basal DNA breaks.

\section{CNPs Sensitize HaCat to Radiation-Induced Cell Death}

$\mathrm{X}$-rays promoted apoptosis on $\mathrm{HaCat}$ cells, starting at $5 \mathrm{~Gy}$ (Figure 3A); an additional intensity at 7 Gy allowed showing a dose-dependent response. Thus, while DNA damage is increasingly induced by all doses, it is able to promote apoptosis only at the higher intensities, suggesting a high threshold level of damage perception for HaCat. Surprisingly, CNPs not only failed to reduce radiation-induced apoptosis, as expected due to their ability to reduce the damage, but even incremented it at 5 and 7 Gy.

To verify the role of CNPs on survival of HaCat to radiation damage, we measured the ability of irradiated HaCat cells to 


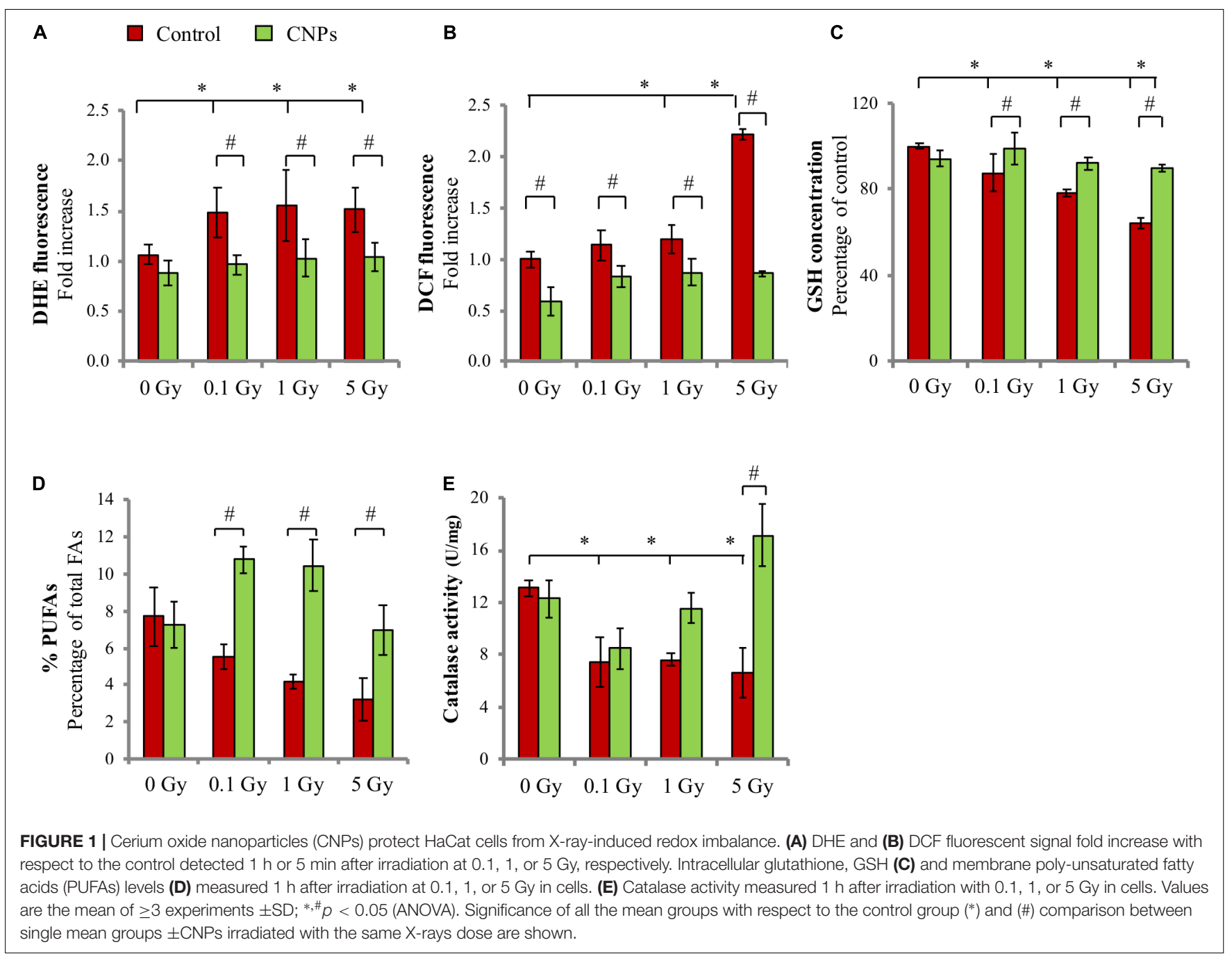

form colonies in the presence and absence of CNPs (clonogenicity assay). As shown in Figure 3B, X-rays strongly reduced colony formation, as expected. The reduction is exacerbated by CNPs: this supports the data on apoptosis, confirming that CNPs reduce cell survival to damage, even in a long time-frame, in spite of their damage-protective effects.

The possibility that the increment of apoptosis may be due to a generic toxic effect of CNPs on HaCat was excluded, because in non-irradiated cells, CNPs poorly affected clonogenicity or apoptosis, or the rate of HaCat cell proliferation (Figure 3C). These data are rather compatible with a scenario where CNPs selectively affect features specifically induced by irradiation, possibly restoring apoptosis competence by nontoxic mechanisms, being in fact radio-sensitizing agents.

With this in mind, we investigated whether CNPs could restore a DNA damage-induced response responsible for apoptosis competence. Cells respond to DNA damage by setting up responses aimed at repairing the damage (DDR) or induce apoptosis (Caputo et al., 2012). This implies blocking cell cycle in the G2 phase (i.e., before mitosis), to give time to complete repair before cell division, avoiding irreversible genetic damage. If repair cannot be accomplished according to the intrinsic integrity checkpoints, cells push themselves to apoptosis. This is a major cancer preventive mechanism; accordingly, in cancer cells the perception of DNA damage, the onset of DDR, and the propensity for the apoptosis outcome are impaired, causing mutation permanence and tumor progression (Hanahan and Weinberg, 2000). So, we investigated whether CNPs radio-sensitization may imply an improvement of the DDR.

We measured the cycle of irradiated HaCat by standard flow cytometric analysis of DNA content. Figure 3D shows the profiles of cell cycles at 0 and $7 \mathrm{~Gy}$, visually showing the abundance of cells in each cell cycle phase. Figure 3E shows the calculated abundance of cells in the G2 phase (as G2/G1 ratio), demonstrating that irradiation at 0.1 and $1 \mathrm{~Gy}$ does not affect cell cycle, whereas 5 and 7 Gy dose-dependently increases cell cycle pausing in G2. Since in our system DSB are produced also by the lowest doses (Figure 2), this means that HaCat have a very high DNA damage threshold level for DDR activation, behaving in this regard like most cancer cells do. In comparison, in normal fibroblasts the cell cycle arrest is complete at radiation intensities as low as $0.1 \mathrm{~Gy}$ (Yang et al., 2005). CNPs do not affect the pause 

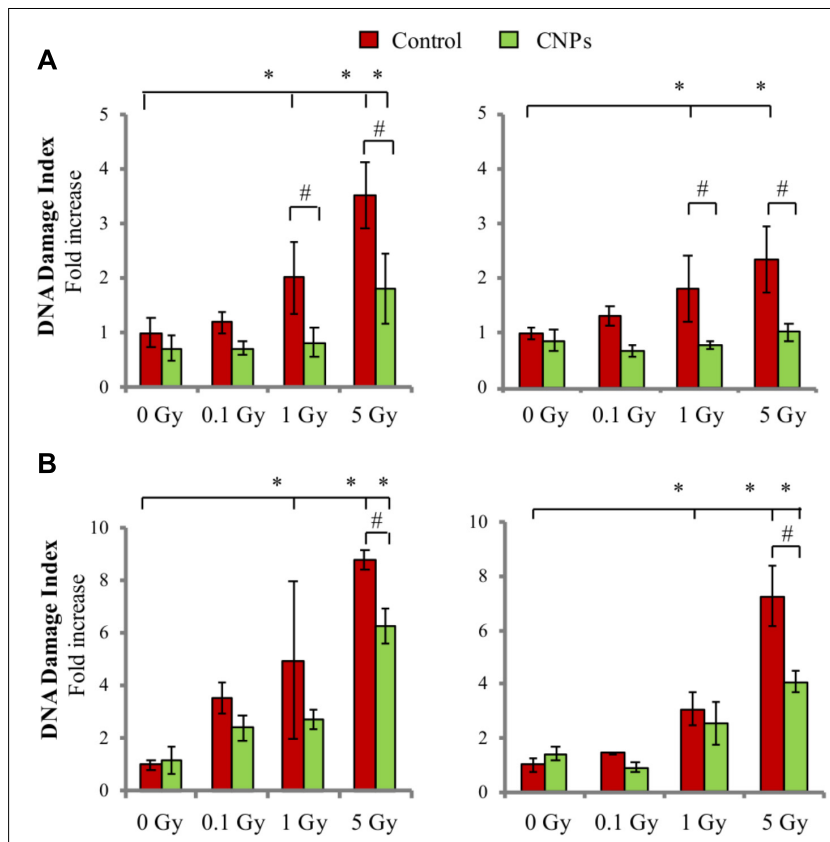

FIGURE 2 | Cerium oxide nanoparticles protect from DNA damage and accelerate DNA repair. SSB and DSB quantification evaluated by alkaline (A) or neutral (B) comet assay $1 \mathrm{~h}$ (Left) or 24h (Right) after X-rays irradiation \pm CNPs. Values are the mean of $\geq 3$ independent experiments $\pm S D$, and are normalized for values of untreated cells; ${ }^{*}, \#<0.05$ (ANOVA). Significance of all the mean groups with respect to the control group $\left(^{*}\right)$ and $(\#)$ comparison between single mean groups \pm CNPs treated with the same $\mathrm{X}$-rays dose are shown.

at $5 \mathrm{~Gy}$, but at 7 Gy they significantly increase the block in G2. The extent of cell cycle blockade depends on the severity of the damage on one side, and on the strength of the cellular response, which is a function of the peculiar asset of specific cells, on the other. Since CNPs reduce radiation damage, this indicates that CNPs act to potentiate the DDR, leading to the apparent paradox of increased response to a reduced damage.

Summarizing, while the radio-protective effect of CNPs deals with providing an extra antioxidant defense to irradiated cells, thus being effective at any intensity of irradiation strong enough to damage cells, the radio-sensitizing effect consists in the magnification of the cell response to DNA damage favoring the apoptotic outcome, indicating that different functions of CNPs may be responsible for these different effects.

\section{CNPs Radio-Sensitizing Ability Occurs Through Oxidation-Independent Mechanisms}

The finding that CNPs increase radio-induced apoptosis argues against a SOD-mimetic effect, because SOD is frankly antiapoptotic (Zhang et al., 2008). Apoptosis impairment is not limited to SOD, but a general effect of antioxidant enzymes [e.g., catalase (Scheit and Bauer, 2014)]: therefore, this raises concerns about the fact that the radio-sensitizing effect of CNPs is actually a redox issue.
To investigate this point, we used a nanotechnology tool that allows discriminating redox vs. non-redox activity of CNPs. We have previously shown that Sm-doped CNPs (SDC), with size and shape similar to the pristine CNPs, are unable to scavenge ROS or to protect cells from oxidative insult due to the loss of the $\mathrm{Ce}^{3+} / \mathrm{Ce}^{4+}$ redox switch (Celardo et al., 2011a; Caputo et al., 2015).

Here the effects of SDC on irradiated HaCat were tested, and it was observed that they fail to prevent X-ray-induced superoxide formation (Figure 4A), confirming the lack of antioxidant effect. SDC were then compared with CNPs for the radiosensitizing effects. Interestingly, SDC maintained the ability of CNPs to increase cell cycle arrest (Figure 4B) and apoptosis (Figure 4C), and to reduce colony formation (Figure 4D), to the same extent as the un-doped nanoparticles do. This indicates that some features of CNPs, different from the wellrecognized antioxidant effect due to the $\mathrm{Ce}^{3+} / \mathrm{Ce}^{4+}$ redox switch, exert a potent biological effect responsible for radiosensitization, enhancing DNA damage perception and apoptotic outcome.

\section{CNPs and SDC Nearly Abrogate $X-R a y-I n d u c e d$ Mutagenesis}

Damaged cells escaping the cell cycle block in G2, undergo mitosis before repair, and this may render permanent an altered genetic asset caused by the damage, thereby promoting mutagenesis. We analyzed mutagenesis by performing the micronuclei assay, a single cell analysis that allows detecting a broad range of genetic alterations, by assessing the frequency of cells containing extra, small nuclear bodies. A peculiar advantage of this technique is the possibility of separately evaluating micronuclei among cells that underwent mitosis, which are recognizable for being bi-nucleated, as cytokinesis is blocked by cytochalasin (Furness et al., 2010): in case of irradiation, bi-nucleated cells identify those that escaped the cell cycle block in G2. As shown in Figure 5, X-rays increase the fraction of micronucleated cells, indicating a pro-mutagenic effect of irradiation, as expected. CNPs and SDC sharply contrast this phenomenon, nearly abolishing mutagenesis.

Decreased mutagenesis may be ascribed to decreased DNA damage on one side, and increased stringency of cellular integrity checkpoints that eliminate highly damaged cells, on the other. CNPs reduced early radiation damage, whereas SDC did not: thus, the fact that SDC and CNPs equally reduce radiation-induced mutagenesis, implies that decreased damage is poorly relevant, pointing instead to increased stringency of the checkpoints as the major determinant for the CNPs-mediated maintenance of genetic integrity.

\section{DISCUSSION}

The main messages from this study are that CNPs are able to act as radiotherapeutic-sensitizing agents by reinforcing the stringency of the cellular DNA integrity 

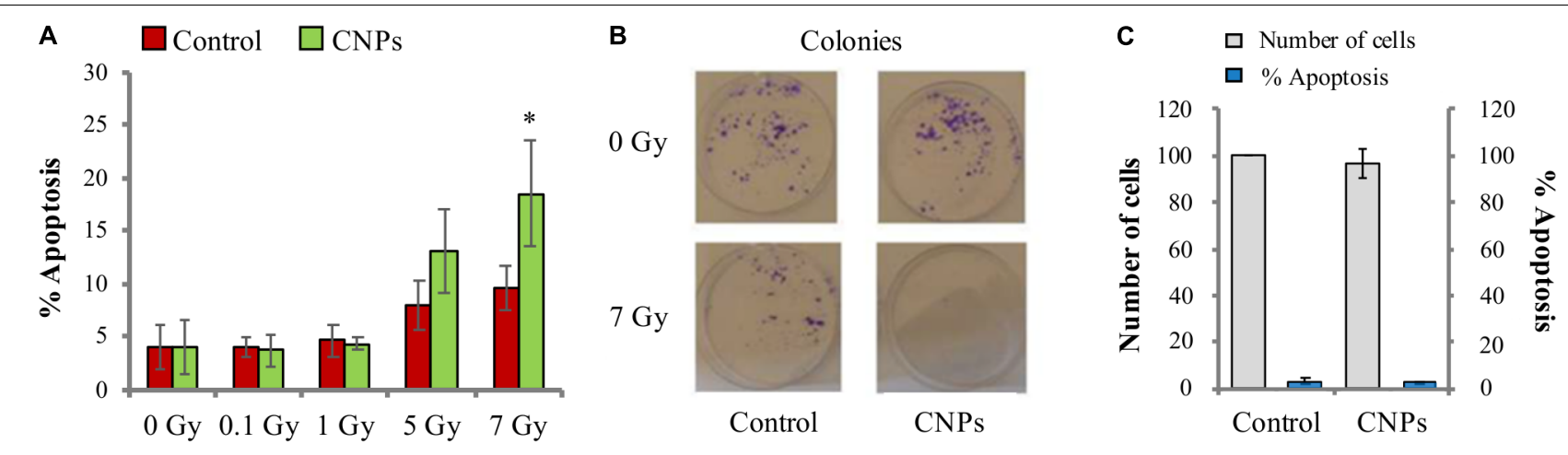

D
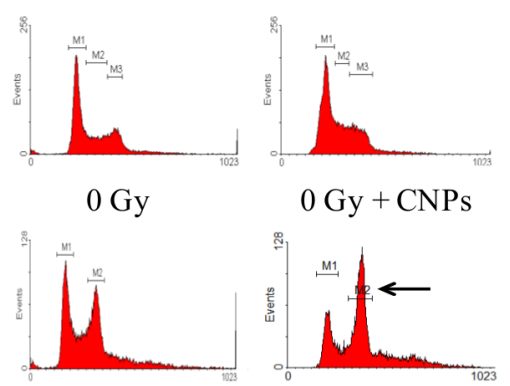

7 Gy
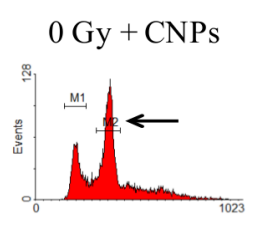

$7 \mathrm{~Gy}+\mathrm{CNPs}$

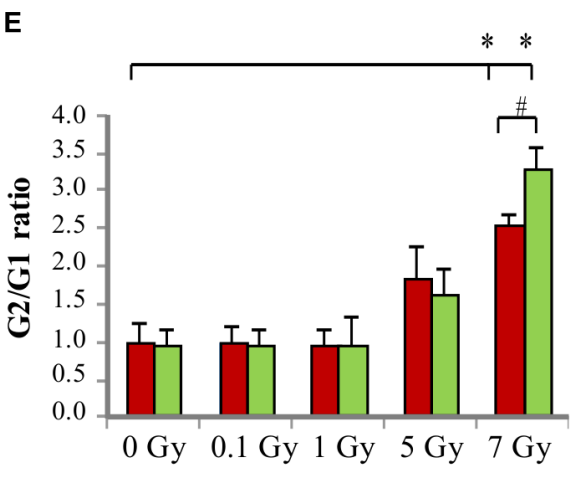

FIGURE 3 | Cerium oxide nanoparticles increase cell response to irradiation. (A) Percentage of X-ray-induced apoptosis on HaCat cells $48 \mathrm{~h}$ after irradiation at 0.1 , 1, 5, or 7 Gy. (B) Number of colonies formed by HaCaT cells irradiated at 7 Gy \pm CNPs. (C) Proliferation (gray) and percentage of apoptosis (blue) of cells treated or not with CNPs for 24 h. (D) Cell cycle profiles of HaCaT cells $24 \mathrm{~h}$ after irradiation at 0-7 Gy \pm CNPs. (E) Dose dependence of G2/G1 ratio measured at $24 \mathrm{~h}$ after irradiation at $0.1,1,5$, or 7 Gy. Values are the mean of $\geq 3$ independent experiments $\pm S D$; *\# $p<0.05$ (ANOVA). Significance of all the mean groups with respect to the control group $\left({ }^{*}\right)$ and $(\#)$ comparison between single mean groups \pm CNPs irradiated with the same X-rays dose are shown.

checkpoints, which is a potent cancer preventive process; and that this effect is driven by a novel, non-redox activity of CNPs.

Radio-sensitization is a major goal in radiotherapy because cancer cells, which should be ideally killed by the highly toxic ionizing radiations used in clinical practice, are instead generally resistant, often evading radiation-induced apoptosis. Therefore, agents or processes that help inducing or incrementing death of irradiated cancer cells may improve the therapeutic outcome, and are highly searched for in prospective clinical application.

"Biological" radio-sensitization may be achieved by interfering with cell survival or apoptotic pathways. For example, DNA repair inhibition hampers survival of DNA-damaged cells that cannot seal the induced lesions, increasing radiationinduced apoptosis; such strategies are receiving much attention nowadays (Ďurišová et al., 2018), even though they do not involve selectivity against cancer cells. A more stringent approach implies specifically hitting intrinsic features of the target cancer cells (e.g., sloppy DNA integrity checkpoints or resistance to apoptosis) during irradiation. Radio-sensitizing agents acting this way have the advantage of increasing cell death selectively in cells with poor apoptosis competence, i.e., cancer cells, sparing the normal cells present in the irradiated area.

Treatments generically allowing achieving a higher level of cancer cell killing with respect to radiation alone (independently of the selectivity), also are considered to be radio-sensitizers. Bioactive nanoparticles, including CNPs, possess several of such radio-sensitizing properties. Nanoparticles made of high atomic number materials, including CNPs, when irradiated with specific energy beams (n.b., different from that used in our study), emit toxic ROS or heat (“dose-enhancement effect"), thus resulting in greater toxicity than irradiation alone, on any cells present in the irradiated area (Misawa and Takahashi, 2011; Caputo et al., 2014). It was reported that CNPs exert on leukemic HL60 cells toxic effects on their own [due to still unexplained mechanism, see (Corsi et al., 2018)], which sum up with that induced by irradiation (Montazeri et al., 2018): this is actually an additional toxicity effect rather than bona fide radio-sensitization. In a further study showing in vitro radio-sensitization of pancreatic cancer cells by CNPs, it was proposed that the acidic environment of the irradiated cells may impair the catalase-mimetic activity of CNPs, causing $\mathrm{H}_{2} \mathrm{O}_{2}$ accumulation and toxicity (Wason et al., 2013); however, this explanation do not consider that to inhibit the catalase 


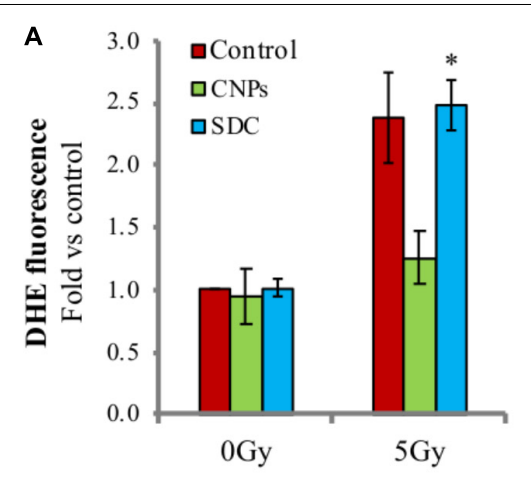

C

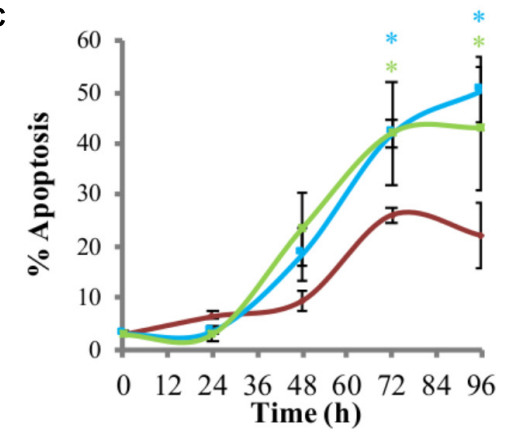

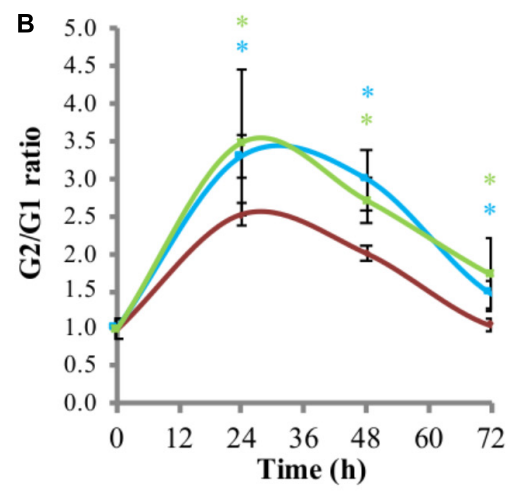

D

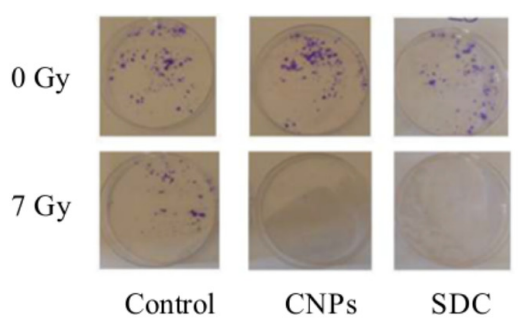

FIGURE 4 | Cerium oxide nanoparticles radio-sensitization is independent from their redox activity. (A) Superoxide levels measured by DHE fluorescent signal detected by flow cytometry $1 \mathrm{~h}$ after irradiation \pm CNPs or SDC at $200 \mu \mathrm{g} / \mathrm{ml}$. (B) Kinetic of cell cycle arrest in cells irradiated at $7 \mathrm{~Gy} \pm$ CNPs or SDC. (C) Time course of X-rays-induced apoptosis on HaCat cells 24-96 h after irradiation at $7 \mathrm{~Gy} \pm \mathrm{CNPs}$ or SCD. Values are the mean of $\geq 3$ independent experiments \pm SD; ${ }^{*} p<0.05$ (ANOVA). Comparison between single mean groups \pm CNPs or SDC irradiated with the same X-rays dose are shown. (D) Colonies (violet spots) formed by HaCaT cells irradiated at 7 Gy \pm CNPs or SDC.

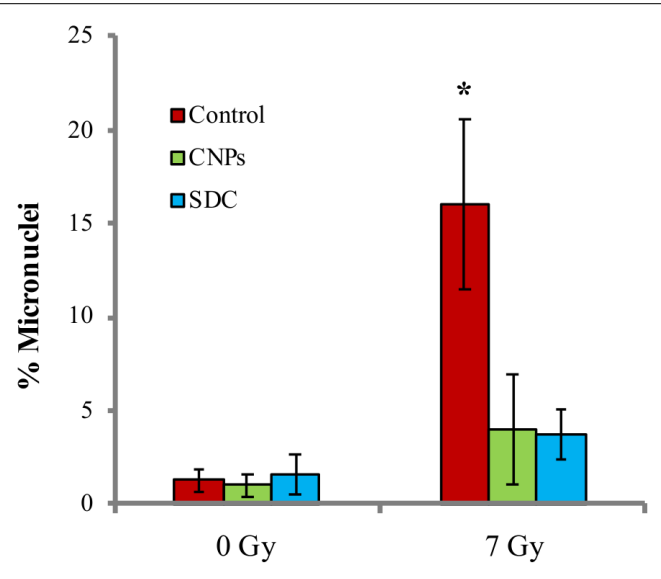

FIGURE 5 | Cerium oxide nanoparticles prevent radiation-induced mutagenesis. Percentage of micronuclei among bi-nucleated cells $24 \mathrm{~h}$ after irradiation at $7 \mathrm{~Gy} \pm \mathrm{CNPs}$. Values are the mean of $\geq 3$ independent experiments $\pm \mathrm{SD}$; ${ }^{*} p<0.05$ (ANOVA). Significance of all the mean groups with respect to the control group is shown.

mimetic CNPs activity it is necessary to reach $\mathrm{pH} \leq 4$, values not compatible with what is found in tissues, even cancerous or irradiated (Corsi et al., 2018). In any case, in our system CNPs not only do not impair catalase activity, but rather, they even restore it when it is destroyed by X-rays, abating ROS formation.

In this study, we describe a CNPs radio-sensitizing activity that does not involve any of the above described mechanisms. Rather, we provide evidence that CNPs are radio-sensitizers in the most stringent sense. On one side, their action is only perceived by cells that are damaged in their DNA, because CNPs were ineffective on non-irradiated $\mathrm{HaCat}$. On the other, they restore apoptosis competence on HaCat cells, which possess a weak DNA damage integrity checkpoint, suggesting that they may have no effect on non-transformed cells equipped with a robust DDR of their own.

The scenario of our in vitro system is reminiscent of cancer cells (with their impaired checkpoints) treated with DNA damaging radio-therapeutic sources of ionizing radiations. The cellular targets of CNPs radio-sensitizing action therefore should be those molecular determinants deployed to the restoration of a DNA integrity checkpoint, responsible for reinforcing both the perception of DNA damage, and the proneness to the apoptotic outcome in case of mal-repair. The DDR is a very well-studied signal transduction process, with complex and branched interactions (Caputo et al., 2012), which is often malfunctioning in cancer cells, allowing cell duplication in spite of DNA damage. This causes accumulation 
of mutations, constituting the molecular bases of cancer progression. A sloppy DNA integrity control may be due to loss or gain of function of specific activators or repressors of DDR, respectively. So, we may speculate that CNPs may either restore or supply a DDR activator function lost in cancer cells, or inhibit an overexpressed signaling pathway aimed at bypassing DDR. The latter is an event that often occurs in the inflammation conditions that predispose to cancer (Ara and Teicher, 1996; Shureiqi and Lippman, 2001), and implies concerted actions preserving cell viability even in the presence of damage (Kidane et al., 2014). We are actively working in this direction to identify possible CNPs target(s) allowing bypassing such deleterious cell survival pathways.

Cerium oxide nanoparticles are considered very promising agents in antioxidant therapy, due to their peculiar autoregenerative antioxidant mechanism (Celardo et al., 2011c). The original aim of this study was to investigate the antioxidant mechanism of CNPs radio-protective effects at the cell and tissue level, considering that cancer microenvironment is deeply affected by redox imbalance (Helfinger and Schröder, 2018; Hegedûsa et al., 2018). The technique of Sm doping was indeed adopted to rule out any other possible effects of CNPs, being in fact originally used as negative control (Celardo et al., 2011b). Surprisingly, however, this tool has allowed pointing out that unexpected nonredox bioactivity of CNPs (Gliga et al., 2017 and this study).

Non-redox activities of CNPs, with different mechanisms, have been described. They include CNPs dissolution, a phenomenon occurring in highly acidic $(\mathrm{pH} \leq 4)$ environments (Schwabe et al., 2014), leading to release of toxic $\mathrm{Ce}^{4+}$ ions (Huang et al., 2010). It is reported that ionizing irradiation in aqueous environment can strongly promote ceria dissolution via acidification, with release of $\mathrm{Ce}^{4+}$ ions (Asghar et al., 2017), hence inducing toxicity. Though potentially logically explaining the selective toxicity against irradiated cells we describe here, some considerations argue against this mechanism as an explanation for our results. Indeed, acidic events leading to CNPs dissolution $(\mathrm{pH} \leq 4)$ would have been easily perceived, being visually detectable through the $\mathrm{pH}$-sensitive dye included in the standard culture media formulations. Moreover, such levels of acidification are incompatible with cell functions or survival (Corsi et al., 2018). Therefore, it remains to be understood which is the non-redox feature of CNPs responsible for the radiosensitizing effect reported here. We cannot exclude that irradiation may re-localize internalized CNPs into the lysosome acidic cell compartment, which have a $\mathrm{pH}$ compatible with CNP dissolution. This may have the consequence of selectively producing a toxic mediator such as $\mathrm{Ce}^{4+}$ ions, previously reported to increase the toxic effect of radiations (Floersheim, 1995), at the very moment when an apoptotic outcome would be welcome as a response to DNA damage. If such a mechanism is compatible with a reduced cell survival to stress, it hardly explains, however, the improved perception of the DNA damage leading to increased cell cycle blockade and apoptosis: therefore, other mechanisms should be investigated to fully understand the role played by CNPs in increasing the stringency of the cell integrity checkpoints.

\section{CONCLUSION}

This study highlights novel perspectives to the actions of CNPs as anticancer and in general medicinal devices, describing new functions in the control of cell signaling. This contributes to the emerging evidence that CNPs may exert a bio-modulatory control of cancer microenvironment, re-establishing apoptosis competence and possibly participating to the anakoinosis communicative reprogramming process that is implicated in the pharmacological restoration of normal homeostasis in cancer tissues (Hart et al., 2015). Overall, our findings pose new questions that we hope will be answered in a reasonable time frame.

\section{AUTHOR CONTRIBUTIONS}

$\mathrm{FaC}$ and $\mathrm{LG}$ wrote the paper. FaC made most cell experiments. FrC performed the experiments and helped with manuscript preparation. VM did the redox measurements and interpreted the results. SB performed PUFA analyses and interpreted the results. AG did all the $\mathrm{X}$-rays exposure and supervised the biological experiments. ET and SL supervised all nanoparticle issues. LG coordinated the project. All authors participated in the development of the scientific work, contributed to discussion on experiments and presentation, and approved the manuscript.

\section{FUNDING}

FaC and FrC were funded by fellowship from the PhD school in Materials for Health, Environment and Energy, University of Rome Tor Vergata.

\section{ACKNOWLEDGMENTS}

$\mathrm{FaC}$ and $\mathrm{FrC}$ are present and former students, respectively, of the PhD school in Materials for Health, Environment and Energy, University of Rome Tor Vergata.

\section{SUPPLEMENTARY MATERIAL}

The Supplementary Material for this article can be found online at: https://www.frontiersin.org/articles/10.3389/fphar. 2018.01183/full\#supplementary-material 


\section{REFERENCES}

Aebi, H. (1984). Catalase in vitro. Methods Enzymol. 105, 121-126. doi: 10.1016/ S0076-6879(84)05016-3

Alili, L., Sack, M., Karakoti, A., Teuber, S., Puschmann, K., Hirst, S., et al. (2011). Combined cytotoxic and anti-invasive properties of redox-active nanoparticles in tumor-stroma interactions. Biomaterials 32, 2918-2929. doi: 10.1016/j. biomaterials.2010.12.056

Ara, G., and Teicher, B. (1996). Cyclooxygenase and lipoxygenase inhibitors in cancer therapy. Prostaglandins Leukotrienes Essent. Fatty Acids 54, 3-16. doi: 10.1016/S0952-3278(96)90075-7

Asghar, M., Inkson, B., and Möbus, G. (2017). Giant radiolytic dissolution rates of aqueous ceria observed in situ by liquid-cell TEM. Chemphyschem 18, 1247-1251. doi: 10.1002/cphc.201601398

Barcellos-Hoff, M., Park, C., and Wright, E. (2005). Radiation and the microenvironment - tumorigenesis and therapy. Nat. Rev. Cancer 5, 867-875. doi: $10.1038 / \mathrm{nrc} 1735$

Borrego-Soto, G., Ortiz-López, R., and Rojas-Martínez, A. (2015). Ionizing radiation-induced DNA injury and damage detection in patients with breast cancer. Genet. Mol. Biol. 38, 420-432. doi: 10.1590/s1415-475738420150019

Boukamp, P., Popp, S., Bleuel, K., Tomakidi, E., Burkle, A., and Fusenig, N. E. (1999). Tumorigenic conversion of immortal human skin keratinocytes (HaCaT) by elevated temperature. Oncogene 18:5638. doi: 10.1038/sj.onc. 1202934

Caputo, F., De Nicola, M., and Ghibelli, L. (2014). Pharmacological potential of bioactive engineered nanomaterials. Biochem. Pharmacol. 92, 112-130. doi: 10.1016/j.bcp.2014.08.015

Caputo, F., De Nicola, M., Sienkiewicz, A., Giovanetti, A., Bejarano, I., Licoccia, S., et al. (2015). Cerium oxide nanoparticles, combining antioxidant and UV shielding properties, prevent UV-induced cell damage and mutagenesis. Nanoscale 7, 15643-15656. doi: 10.1039/c5nr03767k

Caputo, F., Mameli, M., Sienkiewicz, A., Licoccia, S., Stellacci, F., Ghibelli, L., et al. (2017). A novel synthetic approach of cerium oxide nanoparticles with improved biomedical activity. Sci. Rep. 7:4636. doi: 10.1038/s41598-017-04 098-6

Caputo, F., Vegliante, R., and Ghibelli, L. (2012). Redox modulation of the DNA damage response. Biochem. Pharmacol. 84, 1292-1306. doi: 10.1016/j.bcp.2012. 07.022

Celardo, I., De Nicola, M., Mandoli, C., Pedersen, J., Traversa, E., and Ghibelli, L. (2011a). Ce3 + ions determine redox-dependent anti-apoptotic effect of cerium oxide nanoparticles. ACS Nano 5, 4537-4549. doi: 10.1021/nn200126a

Celardo, I., Pedersen, J., Traversa, E., and Ghibelli, L. (2011b). Pharmacological potential of cerium oxide nanoparticles. Nanoscale 3:1411. doi: 10.1039/ c0nr00875c

Celardo, I., Traversa, E., and Ghibelli, L. (2011c). Cerium oxide nanoparticles: a promise for applications in therapy. J. Exp. Ther. Oncol. 9, 47-51.

Colon, J., Hsieh, N., Ferguson, A., Kupelian, P., Seal, S., Jenkins, D., et al. (2010). Cerium oxide nanoparticles protect gastrointestinal epithelium from radiationinduced damage by reduction of reactive oxygen species and upregulation of superoxide dismutase 2. Nanomedicine 6, 698-705. doi: 10.1016/j.nano.2010. 01.010

Corsi, F., Caputo, F., Traversa, E., and Ghibelli, L. (2018). Not only redox: the multifaceted activity of cerium oxide nanoparticles in cancer prevention and therapy. Front. Oncol. 8:309. doi: 10.3389/fonc.2018. 00309

D'Angelo, B., Santucci, S., Benedetti, E., Di Loreto, S., Phani, R., Falone, S., et al. (2009). Cerium oxide nanoparticles trigger neuronal survival in a human alzheimer disease model by modulating BDNF pathway. Curr. Nanosci. 5, 167-176. doi: 10.2174/157341309788185523

Das, S., Dowding, J., Klump, K., McGinnis, J., Self, W., and Seal, S. (2013). Cerium oxide nanoparticles: applications and prospects in nanomedicine. Nanomedicine 8, 1483-1508. doi: 10.2217/nnm.13.133

Ďurišová, K., Ẽecháková, L., Jošt, P., Šinkorová, Z., Kmochová, A., Pejchal, J., et al. (2018). DNA repair inhibitors as radiosensitizers in human lung cells. J. Appl. Biomed. 16, 66-74. doi: 10.1016/j.jab.2017.10.008

Filomeni, G., Rotilio, G., and Ciriolo, M. R. (2002). Cell signalling and the glutathione redox system. Biochem. Pharmacol. 64, 1057-1064. doi: 10.1016/ S0006-2952(02)01176-0
Floersheim, G. (1995). Modification of radiation sensitivity by salts of the metals beryllium and indium and the rare earths cerium, lanthanum and scandium. Radiat. Res. 141:318. doi: 10.2307/3579010

Furness, D., Dekker, G., Hague, W., Khong, T., and Fenech, M. (2010). Increased lymphocyte micronucleus frequency in early pregnancy is associated prospectively with pre-eclampsia and/or intrauterine growth restriction. Mutagenesis 25, 489-498. doi: 10.1093/mutage/ geq032

García, O., Mandina, T., Lamadrid, A., Diaz, A., Remigio, A., Gonzalez, Y., et al. (2004). Sensitivity and variability of visual scoring in the comet assay. Mutat. Res. 556, 25-34. doi: 10.1016/j.mrfmmm.2004.06.035

Ghibelli, L., Nosseri, C., Coppola, S., Maresca, V., and Dini, L. (1995). The increase in $\mathrm{H} 2 \mathrm{O} 2$-induced apoptosis by ADP-ribosylation inhibitors is related to cell blebbing. Exp. Cell Res. 221, 470-477. doi: 10.1006/excr.1995.1398

Giovanetti, A., Deshpande, T., and Basso, E. (2008). Persistence of genetic damage in mice exposed to low dose of $\mathrm{X}$ rays. Int. J. Radiat. Biol. 84, 227-235. doi: 10.1080/09553000801902166

Giri, S., Karakoti, A., Graham, R., Maguire, J., Reilly, C., Seal, S., et al. (2013). Nanoceria: a rare-earth nanoparticle as a novel anti-angiogenic therapeutic agent in ovarian cancer. PLoS One 8:e54578. doi: 10.1371/journal.pone.0054578

Gliga, A., Edoff, K., Caputo, F., Källman, T., Blom, H., Karlsson, H., et al. (2017). Cerium oxide nanoparticles inhibit differentiation of neural stem cells. Sci. Rep. 7:9284. doi: 10.1038/s41598-017-09430-8

Hanahan, D., and Weinberg, R. A. (2000). The hallmarks of cancer. Cell 100, 57-70. doi: 10.1016/S0092-8674(00)81683-9

Hart, C., Vogelhuber, M., Wolff, D., Klobuch, S., Ghibelli, L., Foell, J., et al. (2015). Anakoinosis: communicative reprogramming of tumor systems - for rescuing from chemorefractory neoplasia. Cancer Microenviron. 8, 75-92. doi: 10.1007/ s12307-015-0170-1

Hegedûsa, C., Kovácsb, K., Polgára, Z., Regdona, Z., Szabó, E., Robaszkiewicz, A., et al. (2018). Redox control of cancer cell destruction. Redox Biol. 16, 59-74. doi: 10.1016/j.redox.2018.01.015

Helfinger, V., and Schröder, K. (2018). Redox control in cancer development and progression. Mol. Aspects Med. 63, 88-98. doi: 10.1016/j.mam.2018.02.003

Huang, S., Li, Z., Wang, X., Wang, Q., and Hu, F. (2010). Cerium caused life span shortening and oxidative stress resistance in Drosophila melanogaster. Ecotoxicol. Environ. Saf. 73, 89-93. doi: 10.1016/j.ecoenv.2009. 09.017

Kidane, D., Chae, W., Czochor, J., Eckert, K., Glazer, P., Bothwell, A., et al. (2014). Interplay between DNA repair and inflammation, and the link to cancer. Crit. Rev. Biochem. Mol. Biol. 49, 116-139. doi: 10.3109/10409238.2013. 875514

Lord, M., Tsoi, B., Gunawan, C., Teoh, W., Amal, R., and Whitelock, J. (2013). Anti-angiogenic activity of heparin functionalised cerium oxide nanoparticles. Biomaterials 34, 8808-8818. doi: 10.1016/j.biomaterials.2013. 07.083

Misawa, M., and Takahashi, J. (2011). Generation of reactive oxygen species induced by gold nanoparticles under $\mathrm{x}$-ray and UV irradiations. Nanomedicine 7, 604-614. doi: 10.1016/j.nano.2011.01.014

Montazeri, A., Zal, Z., Ghasemi, A., Yazdannejat, H., Asgarian-Omran, H., and Hosseinimehr, S. (2018). Radiosensitizing effect of cerium oxide nanoparticles on human leukemia cells. Pharm. Nanotechnol. 6, 111-115. doi: 10.2174/ 2211738506666180306161253

O'Brien, N., and Cummins, E. (2010). Ranking initial environmental and human health risk resulting from environmentally relevant nanomaterials. J. Environ. Sci. Health A 45, 992-1007. doi: 10.1080/1093452100377 2410

Park, B., Donaldson, K., Duffin, R., Tran, L., Kelly, F., Mudway, I., et al. (2008). Hazard and risk assessment of a nanoparticulate cerium oxide-based diesel fuel additive-a case study. Inhal. Toxicol. 20, 547-566. doi: 10.1080/ 08958370801915309

Perez, J., Asati, A., Nath, S., and Kaittanis, C. (2008). Synthesis of biocompatible dextran-coated nanoceria with ph-dependent antioxidant properties. Small 4, 552-556. doi: 10.1002/smll.200700824

Sack, M., Alili, L., Karaman, E., Das, S., Gupta, A., Seal, S., et al. (2014). Combination of conventional chemotherapeutics with redox-active cerium oxide nanoparticles-a novel aspect in cancer therapy. Mol. Cancer Ther. 13, 1740-1749. doi: 10.1158/1535-7163.mct-13-0950 
Scheit, K., and Bauer, G. (2014). Synergistic effects between catalase inhibitors and modulators of nitric oxide metabolism on tumor cell apoptosis. Anticancer. Res. 34, 5337-5350.

Schwabe, F., Schulin, R., Rupper, P., Rotzetter, A., Stark, W., and Nowack, B. (2014). Dissolution and transformation of cerium oxide nanoparticles in plant growth media. J. Nanopart. Res. 16, 1-11. doi: 10.1007/s11051-0142668-8

Shureiqi, I., and Lippman, S. M. (2001). Lipoxygenase modulation to reverse carcinogenesis. Cancer Res. 61, 6307-6312.

Tarnuzzer, R., Colon, J., Patil, S., and Seal, S. (2005). Vacancy engineered ceria nanostructures for protection from radiationinduced cellular damage. Nano Lett. 5, 2573-2577. doi: 10.1021/nl052 $024 \mathrm{f}$

Walkey, C., Das, S., Seal, S., Erlichman, J., Heckman, K., Ghibelli, L., et al. (2015). Catalytic properties and biomedical applications of cerium oxide nanoparticles. Environ. Sci. Nano 2, 33-53. doi: 10.1039/C4EN00138A

Wason, M., Colon, J., Das, S., Seal, S., Turkson, J., Zhao, J., et al. (2013). Sensitization of pancreatic cancer cells to radiation by cerium oxide nanoparticle-induced ROS production. Nanomedicine 9, 558-569. doi: 10.1016/ j.nano.2012.10.010
Yang, H., Asaad, N., and Held, D. K. (2005). Medium-mediated intercellular communication is involved in bystander responses of X-ray-irradiated normal human fibroblasts. Oncogene 24, 2096-2103. doi: 10.1038/sj.onc. 1208439

Zhang, X., Epperly, M., Kay, M., Chen, Z., Dixon, T., Franicola, D., et al. (2008). Radioprotection in vitro and in vivo by minicircle plasmid carrying the human manganese superoxide dismutase transgene. Hum. Gene Ther. 19, 820-826. doi: 10.1089/hum.2007.141

Conflict of Interest Statement: The authors declare that the research was conducted in the absence of any commercial or financial relationships that could be construed as a potential conflict of interest.

Copyright (c) 2018 Caputo, Giovanetti, Corsi, Maresca, Briganti, Licoccia, Traversa and Ghibelli. This is an open-access article distributed under the terms of the Creative Commons Attribution License (CC BY). The use, distribution or reproduction in other forums is permitted, provided the original author(s) and the copyright owner(s) are credited and that the original publication in this journal is cited, in accordance with accepted academic practice. No use, distribution or reproduction is permitted which does not comply with these terms. 